\title{
IMOBILIZAÇÃO DE ZYMOMONAS MOBILIS EM CASCA DE ABACAXI E LARANJA VISANDO A PRODUÇÃO DE LEVANA
}

\section{IMMOBILIZATION OF ZYMOMONAS MOBILIS IN PINEAPLE AND ORANGE PEELS TO LEVAN PRODUCTION}

\section{Vidiany Aparecida Queiroz Santos ${ }^{1^{*}}$, Bruna Caroline Silva Lima ${ }^{1}$, Crispin Humberto Garcia Cruz ${ }^{1}$}

\author{
${ }^{1}$ UNESP-Universidade Estadual Paulista Júlio de Mesquita Filho, Departamento de \\ Tecnologia de Alimentos, Rua Cristóvão Colombo, 2265, Jardim Nazareth, \\ 15054000, São José do Rio Preto. São Paulo, Brasil. \\ *Autor para correspondência: E-mail: vidianyqueiroz@yahoo.com.br
}

\begin{abstract}
RESUMO
A imobilização de microrganismos apresenta inúmeras vantagens em relação aos processos fermentativos convencionais e sua eficiência está diretamente relacionada ao suporte de imobilização utilizado, que deve ser atóxico, de baixo custo e apresentar ampla área para adesão microbiana. Considerando as vantagens oferecidas pela imobilização, e a abundância de resíduos agroindustriais no Brasil, o objetivo deste trabalho foi avaliar a eficiência da imobilização de $Z$. mobilis em casca de abacaxi e laranja visando a produção de levana, bem como avaliar a capacidade de reutilização do suporte. Para a imobilização, as cascas foram secas a $70-80{ }^{\circ} \mathrm{C} / 24 \mathrm{~h}$, trituradas e esterilizadas. Em seguida, os frascos contendo as cascas foram inoculados com a bactéria Z. mobilis e adicionados ao meio de imobilização. Estes frascos foram incubados a $150 \mathrm{rpm}$ e $30{ }^{\circ} \mathrm{C} / 24 \mathrm{~h}$. Posteriormente, as cascas foram lavadas e adicionadas em frascos contendo diferentes concentrações de sacarose e o meio de fermentação. A biomassa imobilizada foi determinada por espectrofotometria e a produção de levana foi avaliada após hidrólise ácida em unidades de frutose. As melhores condições para a produção de levana obtidas em ambos os suportes foram utilizadas para fermentações com reaproveitamento do sistema imobilizado durante 10 ciclos de $24 \mathrm{~h}$. Em relação à eficiência de imobilização, a casca de abacaxi apresentou 7,72 g.L $\mathrm{L}^{-1}$ de massa celular seca, enquanto que para a casca de laranja este resultado foi de 4,21 g.L $\mathrm{L}^{-1}$. Para a produção de levana, os maiores valores foram obtidos utilizando casca de laranja como suporte, com 25,91 e 16,75 g.L $\mathrm{L}^{-1}$, e para casca de abacaxi a produção foi de 6,31 g.L. ${ }^{-1}$ e 8,64 g.L. ${ }^{-1}$. Nos experimentos com reaproveitamento do suporte, um aumento na produção de levana foi observado a partir do $6^{\circ}$ ciclo, com máxima produção de 86,17 g.. $\mathrm{L}^{-1}$ no $10^{\circ}$ ciclo para casca de laranja. A casca de abacaxi não foi eficiente para manter o microrganismo viável durante os ciclos de fermentação do suporte.
\end{abstract}

Palavras-chave: Adsorção. Polissacarídeo microbiano. Resíduos. Cascas de frutas. 


\begin{abstract}
Microbial immobilization offers numerous advantages over conventional fermentation processes and its efficiency is directly related to immobilization support, must be nontoxic, low cost and wide display area for microbial adhesion. Considering the advantages of immobilization technique and abundance of agro-industrial waste in Brazil, the aim of this study was to evaluate the immobilization efficiency of $Z$. mobilis in pineapple and orange peels aimed in levan production and evaluate the reuse of immobilization support during 10 cycles. For the immobilization, the peels were dried at $70-80{ }^{\circ} \mathrm{C} / 24 \mathrm{~h}$, crushed and sterilized. Then, the flasks containing the sterilized peels were inoculated with $Z$. mobilis and the immobilization medium. These flasks were incubated in $150 \mathrm{rpm}$ and $30{ }^{\circ} \mathrm{C} / 24 \mathrm{~h}$. Then, the peels were washed and added to flasks containing different sucrose concentrations and the fermentation medium. Immobilized biomass was determined by spectrophotometry and levan production was evaluated after acid hydrolysis in fructose units. The best conditions for levan production obtained in both media were utilized for fermentation with reuse of immobilized system for 10 cycles of $24 \mathrm{~h}$. Regarding the immobilization efficiency, pineapple support presented $7.72 \mathrm{~g} . \mathrm{L}^{-1}$ of dry cell mass, while in the orange peel this result was 4.21 g. $\mathrm{L}^{-1}$. For Levan production, the highest values were obtained using orange peel as support, with 25.91 and 16.75 g.L $\mathrm{L}^{-1}$, and by pineapple support the production was 6.31 g.L $\mathrm{L}^{-1}$ e 8.64 g.L $\mathrm{L}^{-1}$. The experiments with reuse of immobilization supports were observed an increase in levan production from the 6th cycle and maximum production $86.17 \mathrm{~g} . \mathrm{L}^{-1}$ for the 10 th cycle to orange peel. The pineapple support was not enough to maintain viable microorganism during fermentation cycles.

Keywords: Adsorption. Microbial polysaccharide. Wastes. Fruit peels.
\end{abstract}

\title{
1. INTRODUÇÃO
}

A goma levana é um exopolissacarídeo constituído de unidades de frutose, unidas por ligações $\beta 1,4$, com diferentes aplicações na indústria de alimentos e farmacêutica (OLIVEIRA et al., 2007; ERNANDES e GARCIA-CRUZ, 2009).

A produção convencional de levana, utilizando células livres no meio de fermentação, apresenta algumas limitações devido à inibição do microrganismo por condições ambientais do meio. Esta dificuldade é ainda maior quando utilizada a Zymomonas mobilis, que apesar da grande eficiência na conversão de substrato em produto, apresenta alta sensibilidade a contaminações e oscilações nas condições de processo (FU et al., 2009; BEHERA et al., 2010).

A utilização de células imobilizadas de Zymomonas mobilis apresenta inúmeras vantagens, incluindo a proteção celular frente a condições desfavoráveis do meio de fermentação; maior concentração de biomassa no suporte; melhor estabilidade operacional e principalmente aumento na produção (PHISALAPHONG et al., 2007).

Dentre as diferentes metodologias para imobilização celular, pode-se destacar a adsorção, que pode ser realizada por meio de interações iônicas ou por ligações covalentes entre os grupos reativos do suporte e do biocatalisador. Neste tipo de imobilização, os principais suportes utilizados incluem materiais celulósicos como os resíduos agroindustriais (KATCHALSKI-KATZIR; KRAEMER 2000; KOURKOUTAS et al., 2004).

Atualmente diferentes resíduos agroindustriais têm sido testados como suportes de imobilização, como o bagaço de cana, farelo de arroz, sabugos de milho, e cascas de frutas (SANTOS, 2008; YU et al., 2010). No Brasil, há elevado consumo de laranja e abacaxi o que gera grandes quantidades de resíduos, cerca de 8 mil toneladas por ano, que apesar de terem aplicações na produção de ração animal, ainda são considerados um importante problema ambiental (PLESSAS et al., 2007). 
Considerando as vantagens oferecidas pela técnica de imobilização, e a abundância de resíduos agroindustriais no Brasil, o presente estudo teve por objetivo avaliar a utilização de casca de laranja e abacaxi como suportes para a imobilização de Zymomonas mobilis CCT4494 visando a produção da goma levana, bem como avaliar a capacidade de reutilização dos suportes em fermentações subsequentes.

\section{MATERIAL E MÉTODOS}

\subsection{Microrganismo e condições de cultivo}

Foi utilizada a bactéria Zymomonas mobilis CCT 4494, obtida da Coleção de Culturas da Fundação Tropical de Pesquisas e Tecnologia "André Tosello" - Campinas, SP. A bactéria foi mantida em caldo Z. mobilis (CZM), composto por peptona de carne $\left(10 \mathrm{~g}^{-1}\right)$, extrato de levedura $\left(10 \mathrm{~g}^{-1}\right)$, glicose $\left(20 \mathrm{~g}^{-1}\right)$ e $1000 \mathrm{~mL}^{-1}$ de água destilada. A cultura estoque, em meio CZM foi armazenada sob-refrigeração, em temperatura de $10^{\circ} \mathrm{C}$.

Para a pré-fermentação, um tubo da cultura estoque de Z. mobilis foi inoculado em frasco contendo CZM e em seguida, este foi incubado em estufa bacteriológica a $30{ }^{\circ} \mathrm{C} / 24 \mathrm{~h}$. A fermentação, para a produção da goma levana, foi realizada utilizando o meio basal composto por: extrato de levedura $\left(2,5 \mathrm{~g}^{-1}\right), \mathrm{KH}_{2} \mathrm{PO}_{4}\left(0,5 \mathrm{~g}^{-1}\right),\left(\mathrm{NH}_{4}\right)_{2} \mathrm{SO}_{4}\left(0,5 \mathrm{~g}^{-1}\right), \mathrm{MgSO}_{4} \cdot 7 \mathrm{H}_{2} \mathrm{O}\left(0,5 \mathrm{~g}^{-1}\right)$ e 500 $\mathrm{mL}^{-1}$ de água destilada. A este meio, foram adicionadas diferentes concentrações de sacarose (250, 300 e 350 g. $\mathrm{L}^{-1}$ ), previamente esterilizadas a $121{ }^{\circ} \mathrm{C}$ por 15 minutos. As fermentações foram realizadas com o $\mathrm{pH}$ inicial do meio de cultura ajustado para 5,5, em triplicata, com temperaturas de incubação de 30 e $40^{\circ} \mathrm{C}$, sem agitação e com agitação $150 \mathrm{rpm}$, durante 24,48 e $72 \mathrm{~h}$.

\subsection{Preparo e padronização do inóculo}

Para a realização dos ensaios, o conteúdo dos frascos da pré-fermentação (item 2.1) foi centrifugado a 3660 g por 15 minutos, o sobrenadante descartado e o "pellet" de células foi ressuspendido em solução salina $0,85 \%$ esterilizada, obtendo-se uma suspensão celular concentrada. A partir desta suspensão, a concentração de células adicionadas ao suporte foi padronizada por espectrofotometria, de acordo com Vignoli (2003).

\subsection{Imobilização em cascas de laranja e abacaxi}

Foram utilizadas cascas de laranja do tipo Pera Rio (Citrus sinensis L. Osbeck) e cascas de abacaxi do tipo Pérola (Ananas comosus L. Merril). Essas cascas foram fracionadas em tamanho de aproximadamente $0,5 \mathrm{~cm}^{-1}$ e em seguida, foram lavadas com água destilada para a remoção completa de açúcares residuais. A quantidade de açúcares totais, após cada lavagem, foi monitorada utilizando método descrito por Dubois (1956). Após esta etapa, as cascas foram secas em estufa a $70{ }^{\circ} \mathrm{C}$ durante $24 \mathrm{~h}$. Para a imobilização, as cascas foram esterilizadas, e então o inóculo previamente padronizado (item 4.4), foi adicionado juntamente com o meio de imobilização (caldo $\mathrm{ZM}$ ). Estes frascos foram incubados sob agitação de $150 \mathrm{rpm}$ durante $24 \mathrm{~h}$ a $30{ }^{\circ} \mathrm{C}$. Após a imobilização, as cascas foram separadas do meio e lavadas com água destilada esterilizada para a remoção de células não aderidas ao suporte. Em seguida, o sistema imobilizado foi transferido assepticamente para os frascos de fermentação contendo o meio basal e as diferentes concentrações de sacarose.

\subsection{Métodos analíticos}

$\mathrm{O} \mathrm{pH}$ final do caldo foi determinado por potenciometria em pHmetro Digmed DM20. A biomassa livre e imobilizada aos suportes casca de abacaxi e laranja foi determinada por espectrofotometria a $570 \mathrm{~nm}$. A produção de levana foi determinada em unidades de frutose, 
conforme técnica descrita por Viikari (1984). Os açúcares totais foram determinados pelo método fenol-sulfúrico, descrito por Dubois et al. (1956). A capacidade de reutilização dos suportes de imobilização foi realizada com base nos melhores resultados obtidos para a produção de levana em ambos os suportes $\left(350 \mathrm{~g} . \mathrm{L}^{-1}\right.$ de sacarose, $150 \mathrm{rpm}, 30{ }^{\circ} \mathrm{C}$ para as cascas de laranja e $40^{\circ} \mathrm{C}$ para as cascas de abacaxi).

\section{RESULTADOS E DISCUSSÃO}

\subsection{Biomassa imobilizada e livre no meio de fermentação}

Os resultados obtidos para os experimentos realizados utilizando casca de laranja e abacaxi como suporte para a imobilização de Zymomonas mobilis CCT4494 estão apresentados nas Tabelas de 1 a 4 .

A biomassa de Zymomonas mobilis imobilizada em casca de laranja apresentou valores máximos de 3,31 g. $\mathrm{L}^{-1}$ e 0,38 g. $\mathrm{L}^{-1}$, nos experimentos realizados em temperatura de 30 e $40{ }^{\circ} \mathrm{C}$ respectivamente, (Tabelas 1 - 2; Figura 1). Para os ensaios realizados com o suporte casca de abacaxi, os melhores resultados foram 1,66 g. $\mathrm{L}^{-1}$ e 5,51 g. $\mathrm{L}^{-1}$ nos experimentos realizados em temperatura de 30 e $40{ }^{\circ} \mathrm{C}$, respectivamente (Tabelas 3-4; Figura 2).

Tabela 1 - Parâmetros fermentativos obtidos nos experimentos realizados com cascas de laranja como suporte de imobilização, com agitação a 150 rpm e $30^{\circ} \mathrm{C}$.

\begin{tabular}{|c|c|c|c|c|c|c|c|c|c|}
\hline & & $24 \mathrm{~h}$ & & & $48 \mathrm{~h}$ & & & $72 \mathrm{~h}$ & 3 \\
\hline & \multicolumn{9}{|c|}{ Concentração de substrato inicial $\left(\mathrm{g} . \mathrm{L}^{-1}\right)$} \\
\hline & 250 & 300 & 350 & 250 & 300 & 350 & 250 & 300 & 350 \\
\hline $\mathrm{BL}\left(\mathrm{g} \cdot \mathrm{L}^{-1}\right)$ & 0,37 & 0,30 & 0,46 & 0,45 & 0,67 & 1,05 & 0,52 & 0 & 2,23 \\
\hline $\mathrm{BI}\left(\mathrm{g} \cdot \mathrm{L}^{-1}\right)$ & 0,28 & 0,22 & 0,38 & 0,22 & 0,168 & 0,22 & 0,08 & 0,17 & 0,02 \\
\hline $\mathrm{pH}$ & 4,26 & 4,39 & 4,4 & 4,12 & 4,22 & 4,06 & 3,98 & 4,01 & 4,01 \\
\hline $\mathrm{L}\left(\mathrm{g} \cdot \mathrm{L}^{-1}\right)$ & 0,08 & 0,12 & 0,12 & 0,05 & 0,05 & 0,05 & 0,10 & 0,01 & 0,72 \\
\hline CS $\left(\right.$ g..$\left.L^{-1}\right)$ & 0 & 0 & 0 & 0 & 0 & 0 & 0 & 6,58 & 0 \\
\hline
\end{tabular}

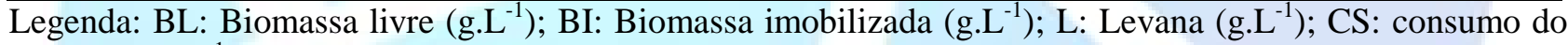
substrato $\left(\mathrm{g} \cdot \mathrm{L}^{-1}\right)$.

Tabela 2 - Parâmetros fermentativos obtidos nos experimentos realizados com cascas de laranja como suporte de imobilização, com agitação a $150 \mathrm{rpm}$ e $40^{\circ} \mathrm{C}$.

\begin{tabular}{|c|c|c|c|c|c|c|c|c|c|}
\hline & & $24 \mathrm{~h}$ & & & $48 \mathrm{~h}$ & & & $72 \mathrm{~h}$ & 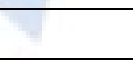 \\
\hline & & \multicolumn{8}{|c|}{ Concentração de substrato inicial (g.L $\left.\mathrm{L}^{-1}\right)$} \\
\hline & 250 & 300 & 350 & 250 & 300 & 350 & 250 & 300 & 350 \\
\hline $\mathrm{BL}\left(\mathrm{g} \cdot \mathrm{L}^{-1}\right)$ & 8,23 & 7,28 & 8,52 & 7,82 & 4,91 & 5,82 & 7,11 & 9,21 & 9,25 \\
\hline BI $\left(\right.$ g. $\left.\mathrm{L}^{-1}\right)$ & 3,31 & 2,81 & 2,36 & 2,24 & 2,47 & 2,04 & 2,22 & 2,22 & 1,58 \\
\hline $\mathrm{pH}$ & 3,81 & 3,76 & 3,73 & 3,79 & 3,79 & 3,76 & 3,83 & 3,795 & 3,86 \\
\hline $\mathrm{L}\left(\mathrm{g} . \mathrm{L}^{-1}\right)$ & 20,26 & 13,94 & 17,36 & 18,52 & 22,25 & 25,92 & 20,71 & 14,47 & 15,79 \\
\hline $\mathrm{CS}\left(\mathrm{g} \cdot \mathrm{L}^{-1}\right)$ & 193,75 & 198,50 & 167,99 & 241,67 & 222,22 & 217,35 & 302,77 & 291,54 & 276,87 \\
\hline
\end{tabular}

Legenda: BL: Biomassa livre (g.L $\left.\mathrm{L}^{-1}\right)$; BI: Biomassa imobilizada (g.L $\left.{ }^{-1}\right)$; L: Levana (g.L $\mathrm{L}^{-1}$ ); CS: consumo do substrato $\left(\mathrm{g} . \mathrm{L}^{-1}\right)$.

Behera et al. (2010) utilizaram alginato para imobilização da bactéria Zymomonas mobilis, que foi cultivada em meio de cultura com $\mathrm{pH}$ ajustado para 6,5 e obtiveram crescimento celular no suporte $\left(1,57\right.$ g. $\left.\mathrm{L}^{-1}\right)$ inferior ao observado em ambos os suportes apresentados nesse estudo. 
Resultado também inferior (1,35 g. $\left.\mathrm{L}^{-1}\right)$ foi observado por $\mathrm{Yu}$ et al. (2010) para experimento utilizando células de Saccharomyces cerevisiae imobilizadas em bagaço de sorgo, visando a produção de etanol.

Tabela 3 - Parâmetros fermentativos obtidos nos experimentos realizados com cascas de abacaxi como suporte de imobilização, com agitação a $150 \mathrm{rpm}$ e $30^{\circ} \mathrm{C}$.

\begin{tabular}{|c|c|c|c|c|c|c|c|c|c|}
\hline & \multicolumn{3}{|c|}{$24 \mathrm{~h}$} & \multicolumn{3}{|c|}{$48 \mathrm{~h}$} & \multicolumn{3}{|c|}{$72 \mathrm{~h}$} \\
\hline \multicolumn{10}{|c|}{ Concentração de substrato inicial (g.L $\left.\mathrm{L}^{-1}\right)$} \\
\hline & 250 & 300 & 350 & 250 & 300 & 350 & 250 & 300 & 350 \\
\hline $\mathrm{BL}\left(\mathrm{g} \cdot \mathrm{L}^{-1}\right)$ & 0,21 & 2,79 & 2,13 & 0,36 & 2,27 & 5,51 & 1,43 & 2,89 & 4,13 \\
\hline BI $\left(\right.$ g. $\left.\mathrm{L}^{-1}\right)$ & 0,01 & 0,01 & 0,01 & 0,01 & 00,1 & 0,01 & 1,66 & 1,57 & 0,01 \\
\hline $\mathrm{pH}$ & 4,2 & 3,98 & 3,88 & 4,2 & 3,95 & 3,77 & 4,14 & 3,87 & 3,8 \\
\hline $\mathrm{L}\left(\mathrm{g} \cdot \mathrm{L}^{-1}\right)$ & 2,14 & 1,21 & 3,75 & 2,05 & 2,96 & 6,31 & 2,64 & 3,36 & 5,47 \\
\hline $\mathrm{CS}\left(\mathrm{g} \cdot \mathrm{L}^{-1}\right)$ & 83,27 & 163,87 & 93,25 & 92,29 & 139,95 & 82,41 & 132,53 & 147,27 & 124,27 \\
\hline
\end{tabular}

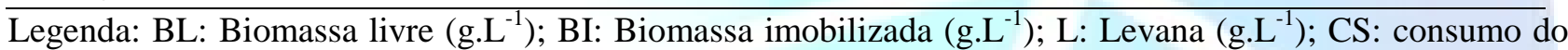
substrato $\left(\mathrm{g} \cdot \mathrm{L}^{-1}\right)$.

Tabela 4 - Parâmetros fermentativos obtidos nos experimentos realizados com cascas de abacaxi como suporte de imobilização, com agitação a $150 \mathrm{rpm}$ e $40^{\circ} \mathrm{C}$.

\begin{tabular}{lllllllllll}
\hline & \multicolumn{9}{c}{ Concentração de substrato inicial $\left(\mathrm{g} . \mathrm{L}^{-1}\right)$} \\
\hline & \multicolumn{9}{c}{} & \multicolumn{9}{c}{ Con } & & & \\
\hline & 250 & 300 & 350 & 250 & 300 & 350 & 250 & 300 & 350 \\
\hline $\mathrm{BL}\left(\mathrm{g} \cdot \mathrm{L}^{-1}\right)$ & 0,01 & 3,27 & 7,73 & 0,01 & 0,79 & 8,92 & 0,01 & 4,76 & 9,55 \\
$\mathrm{BI}\left(\mathrm{g} \cdot \mathrm{L}^{-1}\right)$ & 0,01 & 3,89 & 1,13 & 0,01 & 3,82 & 0,89 & 0,01 & 5,51 & 1,35 \\
$\mathrm{pH}$ & 4,36 & 3,81 & 3,935 & 4,29 & 3,85 & 3,90 & 4,37 & 3,75 & 3,89 \\
$\mathrm{~L}\left(\mathrm{~g} \cdot \mathrm{L}^{-1}\right)$ & 0,15 & 6,14 & 7,45 & 0,15 & 5,10 & 7,95 & 1,33 & 4,32 & 8,64 \\
$\mathrm{CS}\left(\mathrm{g} \cdot \mathrm{L}^{-1}\right)$ & 147,45 & 45,41 & 25,83 & 170,36 & 62,82 & 31,56 & 179,19 & 36,29 & 52,85 \\
\hline
\end{tabular}

Legenda: BL: Biomassa livre (g.L $\left.{ }^{-1}\right)$; BI: Biomassa imobilizada (g.L $\left.{ }^{-1}\right)$; L: Levana (g.L - $^{-1}$ ); CS: consumo do substrato $\left(\mathrm{g} . \mathrm{L}^{-1}\right)$.

Para a biomassa livre, nos experimentos realizados com casca de laranja, os melhores resultados $\left(9,21\right.$ g. $L^{-1}$ e 9,25 g.L $\left.\mathrm{L}^{-1}\right)$ foram obtidos em temperatura de $30{ }^{\circ} \mathrm{C}$, pois esta é a temperatura ótima de crescimento da bactéria. A temperatura de $40^{\circ} \mathrm{C}$ mostrou-se fator limitante para a imobilização de Zymomonas mobilis em cascas de laranja, e atuou como condição estressante, prolongando a fase lag do microrganismo, o que caracterizou seu crescimento exponencial no período de $72 \mathrm{~h}$, conforme demonstrado nas Tabelas 1 e 2 e na Figura 1.

Para o suporte casca de abacaxi verificou-se menores valores para a biomassa livre quando comparados aos obtidos para a casca de laranja (Tabelas 3 e 4). Os máximos valores obtidos foram

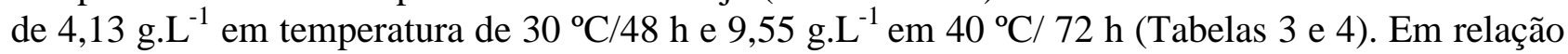
a eficiência da imobilização da bactéria Zymomonas mobilis em cascas de laranja e abacaxi, verificou-se que os maiores valores de biomassa aderida ao suporte foram obtidos utilizando cascas de laranja como suporte (Figura 1). 


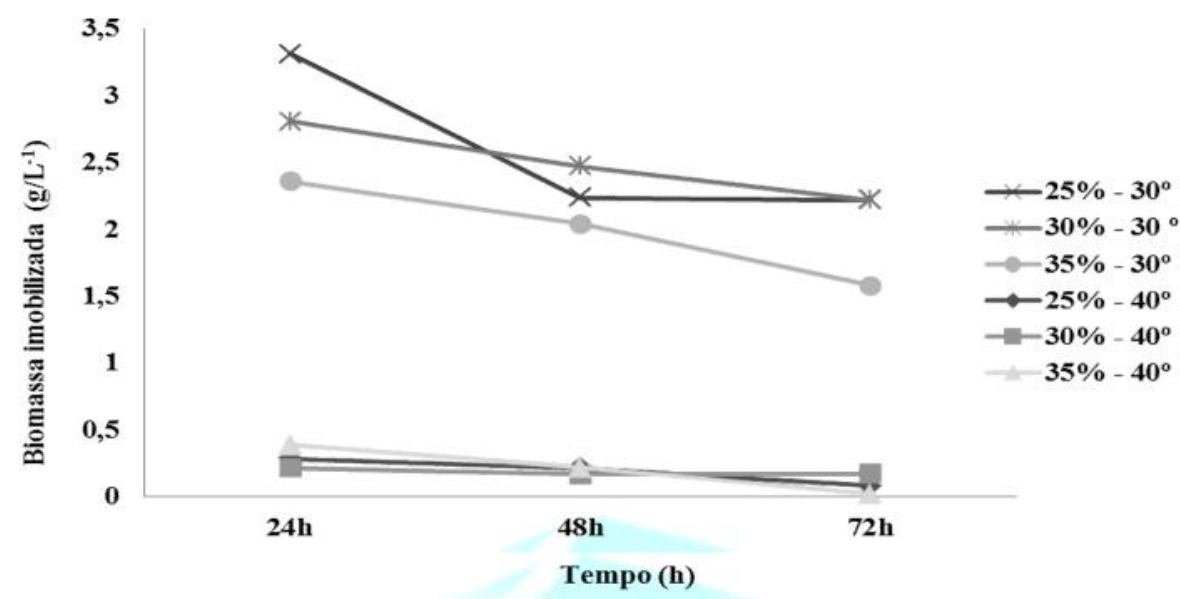

Figura 1. Biomassa de Zymomonas mobilis CCT 4494 imobilizada em cascas de laranja em diferentes concentrações de sacarose, 30 e $40^{\circ} \mathrm{C}$ nos tempos de 24,48 e 72 horas.

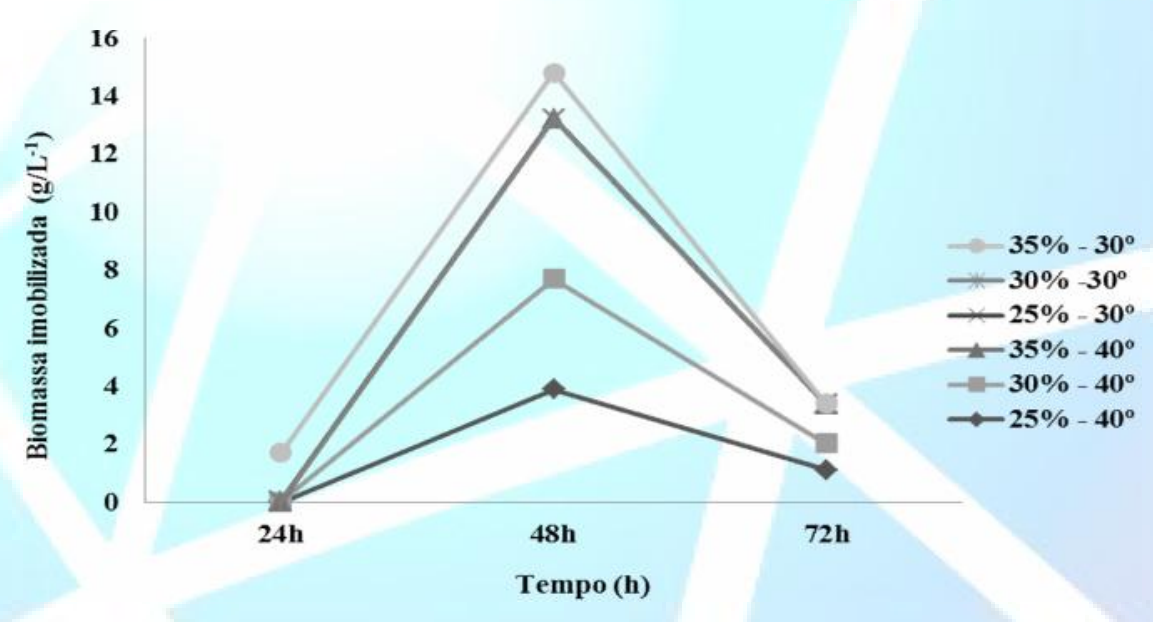

Figura 2. Biomassa da bactéria Zymomonas mobilis CCT 4494 imobilizada em cascas de abacaxi em diferentes concentrações de sacarose a 30 e $40^{\circ} \mathrm{C}$ nos tempos de 24,48 e 72 horas.

\subsection{Comportamento do pH final do meio de fermentação e consumo do substrato sacarose}

$\mathrm{O}$ pH final do meio de fermentação, nos ensaios realizados com cascas de laranja apresentou valores entre 3,76-3,86 e 3,98- 4,39 nos experimentos realizados a temperatura de 30 e $40{ }^{\circ} \mathrm{C}$, respectivamente (Tabelas 1 e 2). Para os experimentos realizados utilizando cascas de abacaxi, foram observados maiores valores de $\mathrm{pH}$ nas primeiras horas de fermentação. Tais resultados foram de respectivamente, 3,77- 4,2 e 3,75-4,36 para temperaturas de 30 a $40{ }^{\circ} \mathrm{C}$ (Tabelas 3 e 4). Esta oscilação pode ser explicada pela morte celular, que teve ação tamponante sobre o meio (VIIKARI e GISLER, 1986; VIGANTS et al., 2001; BORSARI et al., 2006; OLIVEIRA et al., 2007; SHIH et al., 2010).

Os experimentos realizados com cascas de laranja apresentaram valores de $\mathrm{pH}$ final em torno de 4,0, próximo aos valores característicos de crescimento da bactéria Zymomonas mobilis, conforme descrito nas Tabelas 1 e 2 . Independente da concentração inicial de sacarose, houve redução nos valores de $\mathrm{pH}$ nos tempos de fermentação, sendo os menores valores observados com $72 \mathrm{~h}$ para ambos os suportes (Tabelas 1 a 4 ). 
Tal queda nos valores de $\mathrm{pH}$ do caldo fermentativo pode ser explicada pela produção de metabólitos resultantes do desenvolvimento da bactéria. Swings e De Ley (1977) explicaram que esse microrganismo, quando em meios com altas concentrações de sacarose, tem maior capacidade para produção de subprodutos como levana, sorbitol, lactato, acetaldeído, glicerol, acetoína, dihidroxicetona, manitol, e os ácidos acético e glicônico, que podem atuar como acidificantes do meio (DOELLE et al., 1993).

Com relação ao consumo do substrato sacarose, nos experimentos realizados utilizando a bactéria Zymomonas mobilis imobilizada em casca de laranja verificou-se maior consumo de sacarose, com conversão de 320,77 g.L $\mathrm{L}^{-1}$, enquanto que para o suporte casca de abacaxi, a máxima conversão foi de 179,19 g.L $\mathrm{L}^{-1}$ (Tabelas 1 e 4 ).

\subsection{Produção de levana pelo sistema imobilizado em cascas de laranja e abacaxi}

Os maiores valores de produção de levana para imobilização em cascas de laranja foram obtidos para as condições de 350 g. $\mathrm{L}^{-1}$ de sacarose, $30^{\circ} \mathrm{C}, 150 \mathrm{rpm}$ e ausência de agitação $(25,91 \mathrm{e}$ 16,75 g.L $\mathrm{L}^{-1}$, respectivamente), conforme demonstrado nas Tabelas 1 e 2 e Figura 3.

Nos experimentos com temperatura de $40{ }^{\circ} \mathrm{C}$ verificou-se baixa produção, tendo como valor máximo 1,65 g.L $\mathrm{L}^{-1}$, também a 350 g. $\mathrm{L}^{-1}$ de sacarose. Isso indica que tal condição não foi adequada para a síntese de levana, assim como observado para a biomassa imobilizada (Tabelas 1e 2 e Figura 3).

Em concordância com os valores máximos citados anteriormente, as mesmas condições de agitação e concentração de sacarose também favoreceram a produção de levana quando utilizado o suporte casca de abacaxi, porém, os maiores valores foram obtidos nos experimentos realizados utilizando $40^{\circ} \mathrm{C}\left(8,64\right.$ g.L $\mathrm{L}^{-1}$ e 7,94 g.L $\left.{ }^{-1}\right)$, conforme Figura 4.

Para a imobilização em cascas de abacaxi constatou-se baixa produção nessa mesma condição de temperatura e agitação, porém, a uma concentração de $25 \%$ de sacarose (Figura 4), sendo 0,15 g. $\mathrm{L}^{-1}$. Também, nessa condição, pode-se observar um dos menores valores de biomassa imobilizada no suporte, conforme destacado na Tabela 4.

Os valores máximos obtidos para a produção de levana, em concentração de 350 g.L $\mathrm{L}^{-1}$ são citados por diferentes autores como a melhor condição para a síntese de levana, uma vez que esse microrganismo quando na presença de elevadas concentrações de sacarose desvia sua via metabólica produzindo levana e sorbitol em quantidades consideráveis, diminuindo a síntese de etanol (SWINGS e DE LEY, 1977).

Viikari e Gisler (1986) verificaram a correlação entre a síntese de levana, a concentração de sacarose do meio e a quantidade metabolizada pela célula. Sprenger (1996) descreveu que a síntese de levana pela bactéria Zymomonas mobilis é potencializada em meio fermentativo com alta concentração de sacarose. Este comportamento foi também observado no presente trabalho para ambos os suportes de imobilizado, conforme demonstrado nas Figuras 3 e 4.

Resultados superiores aos verificados no presente estudo, tanto para o suporte casca de laranja quanto para casca de abacaxi, foram observados por Shih et al. (2010), os quais imobilizaram Bacillus subtilis nato em esferas de alginato, e verificaram máxima produção no terceiro reciclo $\left(70,6 \mathrm{~g} . \mathrm{L}^{-1}\right)$ com controle de $\mathrm{pH}$ inicial e suplementação do meio com nitrogênio orgânico durante os 5 ciclos de reutilização cada um com 72 h. Estes autores observaram que as esferas permaneceram estáveis durante os cinco ciclos de fermentação.

Resultados inferiores aos obtidos no presente estudo, para o suporte casca de laranja, foram obtidos por Bekers et al. (2001) com produção de levana de 8,5-13,6 g.L.-1 utilizando concentração de sacarose de 100 g. $\mathrm{L}^{-1}$ e pH ajustado a 4,9, com a bactéria Zymomonas mobilis imobilizada em esferas de alginato sem submeter o meio a agitação. 
Os resultados obtidos demonstraram que as cascas de abacaxi não foram eficientes para a fixação das bactérias durante o processo de produção de levana quando comparadas com as de laranja, uma vez que esta última apresentou ou maiores valores de produção (Figura 4).

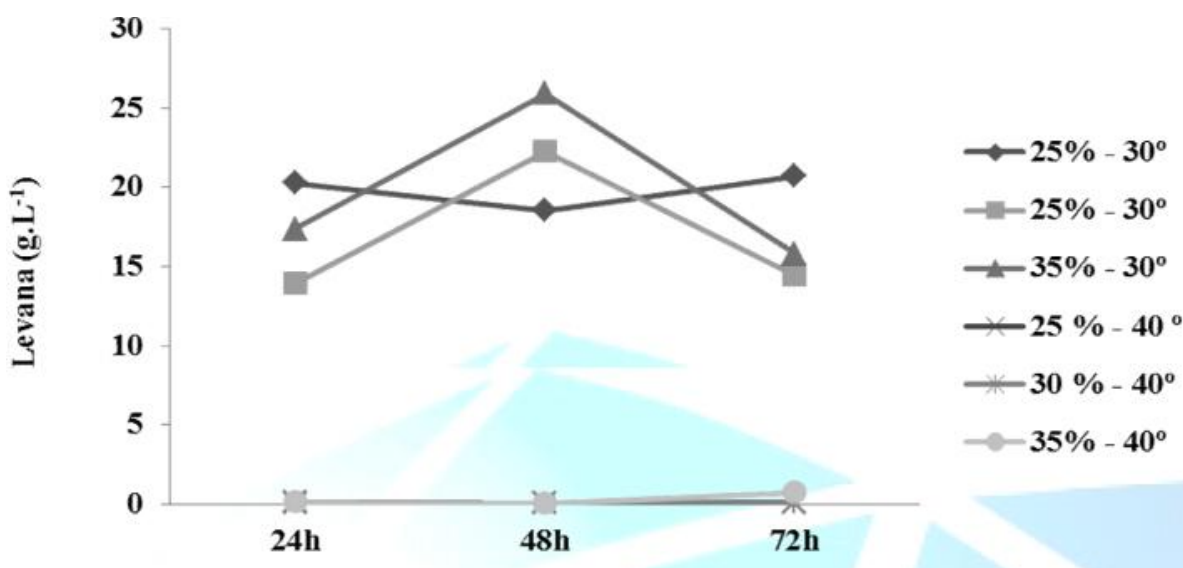

Tempo (h)

Figura 3. Produção de levana pela bactéria Zymomonas mobilis CCT 4494 imobilizada em cascas de laranja em diferentes concentrações de sacarose, 30 e $40{ }^{\circ} \mathrm{C}$ nos tempos de 24,48 e 72 horas.

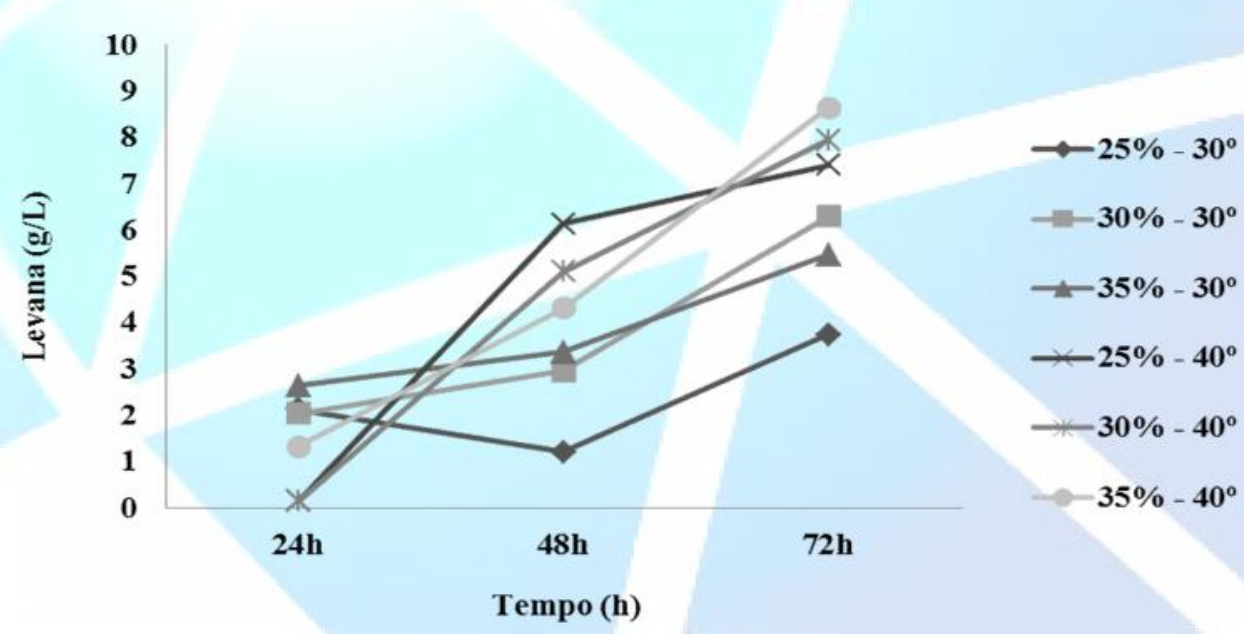

Figura 4. Produção de levana pela bactéria Zymomonas mobilis CCT 4494 imobilizada em cascas de abacaxi em diferentes concentrações de sacarose, 30 e $40^{\circ} \mathrm{C}$ nos tempos de 24,48 e 72 horas.

\subsection{Reciclo dos suportes de imobilização}

A partir das melhores condições obtidas para produção de levana nos experimentos realizados por batelada, foram realizados 10 ciclos de reutilização do sistema imobilizado, cada um com $24 \mathrm{~h}$ de fermentação. As melhores condições para as cascas de laranja e abacaxi foram de respectivamente, 30 e $40{ }^{\circ} \mathrm{C}$ e 350 g.L $\mathrm{L}^{-1}$ de sacarose (Tabelas 1 a 4 ).

\subsubsection{Biomassa livre e imobilizada nas cascas de laranja e abacaxi}

Para ambos os suportes foi determinada a biomassa imobilizada no primeiro e último ciclo de reutilização. O suporte casca de laranja, logo após 24 h de fermentação ( $1^{\circ}$ ciclo), apresentou biomassa imobilizada de $0,63 \mathrm{~g} . \mathrm{L}^{-1}$ e $0,59 \mathrm{~g} . \mathrm{L}^{-1}$ no último ciclo de reutilização. Utilizando as cascas 
de abacaxi houve resultado inverso, verificou-se $0,01 \mathrm{~g} . \mathrm{L}^{-1}$ de células imobilizadas no primeiro ciclo e 0,8 g. $\mathrm{L}^{-1}$ no décimo ciclo de reutilização do suporte.

Este comportamento observado para as cascas de abacaxi pode ser devido à desintegração gradativa que o suporte sofreu durante os ciclos de reutilização do suporte. Em contrapartida, as cascas de laranja permaneceram íntegras durante todo o processo, o que pode ter favorecido o crescimento da bactéria no meio. Tal efeito foi evidenciado visualmente pela observação de grande turvação no caldo fermentativo, o que por sua vez, não foi observado para os experimentos realizados com as cascas de abacaxi.

Em relação a biomassa livre no meio de fermentação, conforme destacado na Figura 5, houve maior crescimento de biomassa livre para o suporte casca de laranja $\left(7,39\right.$ g. $\left.\mathrm{L}^{-1}\right)$, em relação a casca de abacaxi $\left(0,86\right.$ g. $\left.\mathrm{L}^{-1}\right)$, sendo que para este último suporte houve redução gradativa até $0,01 \mathrm{~g} . \mathrm{L}^{-1}$. Com base nestas informações, o suporte casca de abacaxi se apresentou inviável para utilização em fermentações sequenciais com reciclo dos suportes, uma vez que houve baixa adesão microbiana e desintegração do suporte durante os ciclos fermentativos. Em contrapartida, a casca de laranja foi eficiente na imobilização e manutenção da viabilidade microbiana durante os 10 ciclos de reutilização do suporte, havendo desprendimento nos últimos ciclos devido ao processo contínuo de agitação.

3.4.2. Comportamento do $\mathrm{pH}$ final do meio de cultivo e consumo de substrato sacarose durante os ciclos de reutilização dos suportes

$\mathrm{O}$ pH final do meio de fermentação nos ciclos iniciais de reutilização dos suportes mantevese praticamente constante e nos ciclos intermediários houve maior redução nos valores de $\mathrm{pH}$, indicando alta atividade celular. Porém, nos últimos ciclos os valores de $\mathrm{pH}$ final aumentaram para 4,17 no suporte casca de abacaxi e 3,5 para as cascas de laranja, indicando provavelmente lise celular (Figura 6).

Com relação ao consumo de substrato, os maiores valores foram obtidos nas primeiras $24 \mathrm{~h}$ de reutilização para ambos os suportes, com 313,29 g.L.-1 e 313,26 g.L . $^{-1}$ para cascas de abacaxi e cascas de laranja, respectivamente (Figura 7). Este consumo permaneceu quase constante durante os 10 ciclos de $24 \mathrm{~h}$, porém, essa constância foi mantida em maiores valores quando utilizadas células de Zymomonas mobilis imobilizadas em cascas de laranja (276,48 g.L $\mathrm{L}^{-1}$ ) (Figura 7). Tal resultado concorda com os maiores valores de levana observados para este suporte, indicando que o consumo do substrato foi direcionado para produção do biopolímero levana.

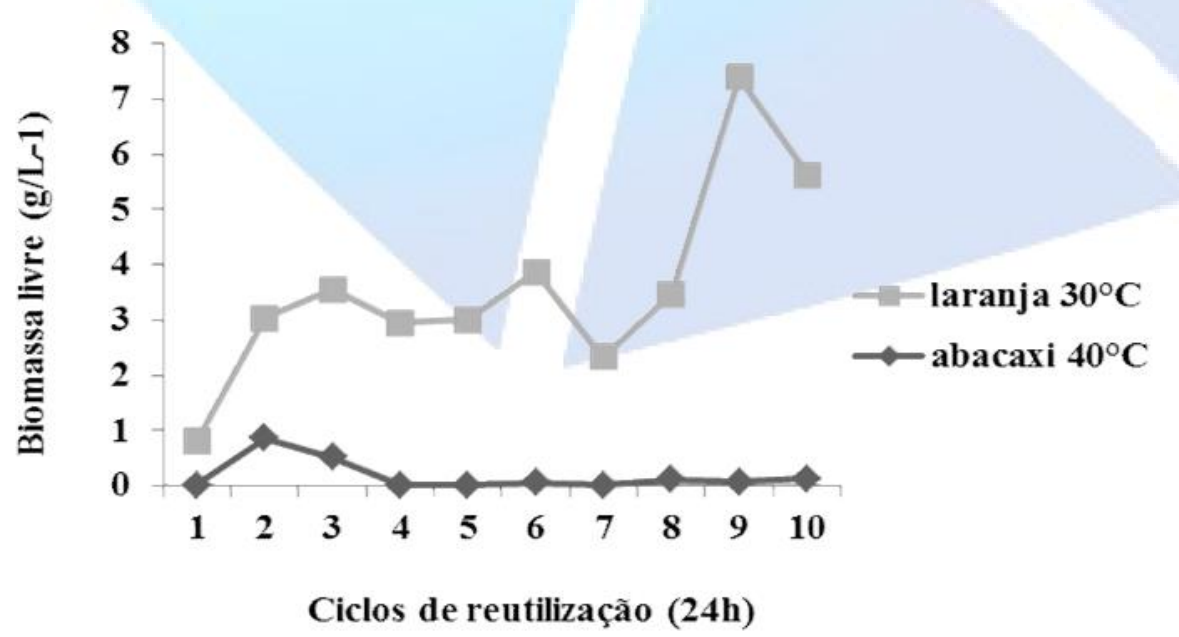

Figura 5. Biomassa da bactéria Zymomonas mobilis no caldo de fermentação durante os ciclos de reutilização. 
Para as cascas de abacaxi, mesmo com elevado consumo de substrato durante os 10 ciclos de reutilização do suporte, observou-se que esse consumo não foi dirigido para a produção do biopolímero nem para o crescimento da bactéria no suporte. Neste caso, o microrganismo pode ter desviado sua via metabólica para a síntese de etanol, sorbitol, lactato, acetaldeído, glicerol, acetoína, di-hidroxicetona, manitol, e os ácidos acético e glicônico (GROHMANN et al., 1994; PLESSAS et al., 2007).

\subsubsection{Produção de levana durante os ciclos de reutilização dos suportes}

O suporte casca de abacaxi apresentou-se ineficaz para a produção de levana durante os ciclos de reutilização do suporte, sendo $1,37 \mathrm{~g} . \mathrm{L}^{-1}$ o maior valor obtido, conforme demonstrado na Figura 7. Para os experimentos realizados utilizando cascas de laranja como suporte de imobilização, verificou-se máxima produção de 86,17 g.L ${ }^{-1}$ (Figura 7).

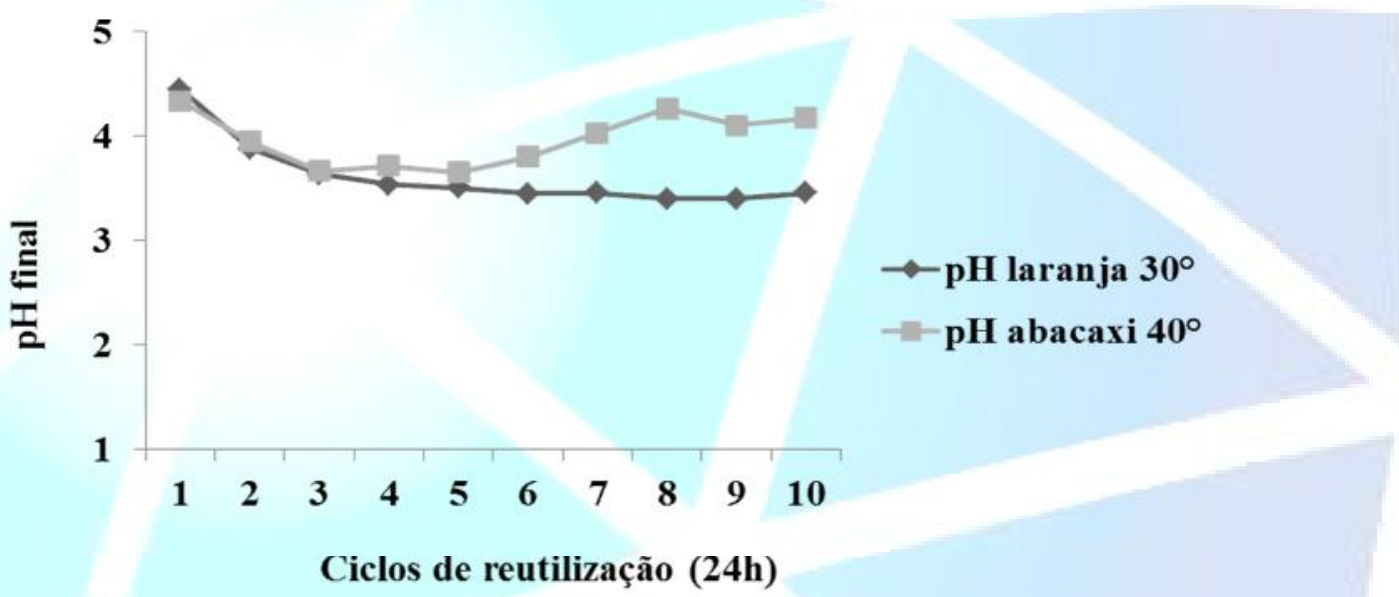

Figura 6. Comportamento do $\mathrm{pH}$ final do meio de cultivo, fermentado por Zymomonas mobilis imobilizada em cascas de laranja e abacaxi durante os ciclos de reutilização.

Crittenden e Doelle (1994) citaram que a temperatura é um importante fator na produção de levana devido à baixa estabilidade térmica da enzima levanasacarase e ainda destaca que em temperaturas acima de $35^{\circ} \mathrm{C}$ pode ocorrer perda irreversível na atividade dessa enzima. Esta informação pode justificar os altos índices de levana observados nos ensaios realizados a temperatura de $30{ }^{\circ} \mathrm{C}$, utilizando cascas de laranja como suporte, bem como os baixos valores obtidos utilizando o suporte casca de abacaxi, cujos experimentos foram realizados a temperatura de $40^{\circ} \mathrm{C}$.

Vale ressaltar também que em experimentos com reciclo do sistema imobilizado o microrganismo permanece por longo tempo exposto as condições de cultivo, o que não é observado nos experimentos por batelada, onde a exposição a alta temperatura é menos intensa e pode ter sido fator estimulante e não inibidor para a produção (Figuras 4 e 7).

A elevada produção de levana utilizando 350 g.L. $\mathrm{L}^{-1}$ de sacarose, é citada por diferentes autores, os quais destacam que nestas condições, o microrganismo desvia sua via metabólica e após hidrolisar a sacarose em unidades de frutose e glicose, inicia a transfrutosilação de unidades de frutose em ligações $\beta(2,6)$, formando a cadeia de levana (VIIKARI e GISLER, 1986; VIGANTS et al., 2001; BORSARI et al., 2006; OLIVEIRA et al., 2007; SHIH et al., 2010).

Os maiores resultados obtidos para o consumo do substrato foram acompanhados pelos maiores valores de produção de levana nos últimos ciclos de reutilização, indicando que o substrato 
foi utilizado para a síntese do biopolímero. Este comportamento também foi observado para o experimento 1 .

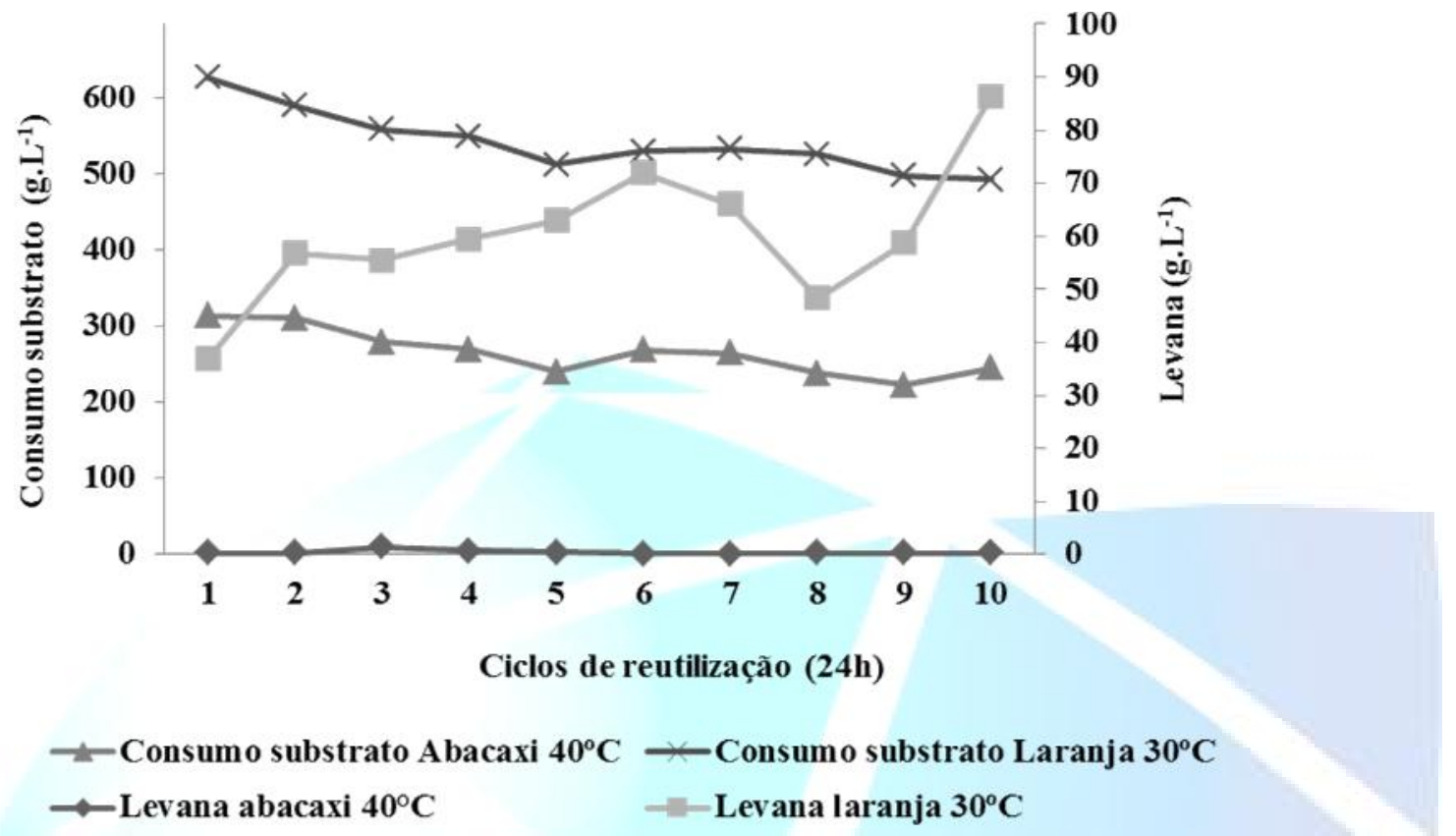

Figura 7. Consumo de substrato sacarose e produção de levanan pela bactéria Zymomonas mobilis durante os ciclos de reutilização dos suportes de imobilização.

\section{CONCLUSÕES}

A casca de laranja foi o suporte mais eficiente para a imobilização e síntese de levana, uma vez que foram obtidos os maiores resultados para biomassa imobilizada, levana e consumo do substrato, tanto para os experimentos realizados por batelada, quanto para aqueles conduzidos por batelada sequencial com reutilização da biomassa imobilizada. A casca de abacaxi, por sua vez, apresentou-se ineficiente para processos fermentativos com reciclo do suporte de imobilização.

\section{REFERÊNCIAS}

BEHERA, S.; RAY, R.C.; MONHANTY, R.C. Comparative study of bioethanol production from mahula (madhuca latifolia) flowers by immobilized cells of Saccharomyces cerevisiae and Zymomonas mobilis in calcium alginate beads. Journal of Science Industrial Research. New Delhi, v. 69, n. 6, p. 472-475, 2010.

BEKERS, M.; LAUKEVICS, J.; KARSAKEVICH, A.; VENTINA, E.; KAMINSKA, E.; UPITE, D.; VINA, I.; LINDE, R.; SCHERBAKA R. Levan-ethanol biosynthesis using Zymomonas mobilis cells immobilized by attachment and entrapment. Process Biochemistry, Oxford, v. 36, n. 10, p. 979-989, 2001.

BORSARI, R.R.J.; CELLIOGI, M.A.P.C.; BUZATO, J.B.; SILVA, R.S.S.F. Influence of carbon source and the fermentation process on levan production by Zymomonas mobilis analyzed by the 
surface response method. Ciência e Tecnologia de Alimentos, Campinas, v. 26, n. 3, p.604-609, 2006.

CRITTENDEN, R.G. E DOELLE, H.W. Identification and characterization of the extracellular sucrases of Zymomonas mobilis UQM 2716 (ATCC 39676). Applied Microbiology

Biotechnology, New York, v. 41, n. 3, p. 302-308, 1994.

DOELLE, H.W.; KIRK, L.; CRITTENDEN, R.; TOH, H.; DOELLE, M.B. Zymomonas mobilis: science and industrial application. Critical Reviews in Biotechnolology. Philadelphia, v. 13, n. 1, p.57-98, 1993.

DUBOIS, M.; GILLES, K.A.; HAMILTON, J.K. Colorimetric method for determination sugars and related substances. Analytical Chemistry, Washington, v. 28, n. 3, p. 350-356, 1956.

ERNANDES, F. M. P. G.; GARCIA-CRUZ, C. H. Análise dos parâmetros cinéticos para produção de levana por Zymomonas mobilis utilizando fermentação submersa. Acta Scientarium Technology. v. 31, n. 1, p. 35-41, 2009.

FU, N.; PEIRIS, P.; MARKHAM J.; BAVOR, J. A novel co-culture process with Zymomonas mobilis and Pichia stipitis for efficient ethanol production on glucose/xylose mixture. Enzyme and Microbiology Technology, New York, v. 45, n. 3, p. 210, 2009.

GROHMANN, K., BALDWIN, E.A., BUSLIG, B.S., INGRAM, L.O. Fermentation of galacturonic acid and other sugars in orange peel hydrolysates by the ethanologenic straw of Escherichia coli. Biotechnology Letters, Dordrecht, v. 16, n. 3, 281-286, 1994.

KATCHALSKI-KATZIR, E., KRAEMER, D.M. Eupergit ${ }^{\circledR}$ C, a carrier for immobilization of enzymes of industrial potential. Journal of Molecular Catalysis B-Enzymatic, Amsterdam, v.10, n. 1-3, 157-176, 2000.

KOURKOUTAS, Y.; BEKATOROU, A.; BANAT, I.M., MARCHANT, R.; KOUTINAS, A.A. Immobilization technologies and support materials suitable in alcohol beverages production: a review. Food Microbiology, London, v. 21, n. 4, 337-397, 2004.

OLIVEIRA, M.R.; SILVA, R.S.S.F.; BUZATO, J.B.; CELLIGOI, M.A.P.C. Study of levan production by Zymomonas mobilis using regional low-cost carbohydrate sources. Biochemical Engineering Journal, Lausanne, v. 37, n. 2, p. 177-183, 2007.

PLESSAS, S.; BEKATOROU, A.; KOUTINAS, M.; SOUPIONI; BANAT, I.M.; MARCHANT, R. Use of Saccharomyces cerevisiae cells immobilized on orange peel as biocatalyst for alcoholic fermentation. Bioresource Technology, Oxford, v. 98, n. 4, p. 860-865, 2007.

PHISALAPHONG, M.; BUDIRAHARJO, R.; BANGRAK, P.; MONGKOLKAJIT, J.; LIMTONG, S. Alginate-Loofa as Carrier Matrix for Ethanol Production. Journal Bioscience Bioengineering, Osaka, v. 104, n. 3, p. 214-217, 2007.

SANTOS, A.M. Fermentação alcoólica com levedura imobilizada em colmos de bambu e em fibra de coco. 2008. S237f. Dissertação (Mestrado em Engenharia Química) - Universidade Federal de Alagoas, Maceió, 2008. 
SPRENGER, G.A. Carbohydrate metabolismo in Zymomonas mobilis: a catabolic higway with some scenic routes. FEMS Microbiology Letters, Amsterdam, v. 145, n. 3, p. 301-307, 1996.

SHIH, I.L., CHEN, L.D., WU, J.Y. Levan production using Bacillus subtilis natto cells immobilized on alginate. Carbohydrate Polymers, Oxford, v. 82, n. 1, p. 111-117, 2010

SWINGS, S.; DE LEY, J. The biology of Zymomonas. Bacteriological Reviews, Washington, v. 41, n. 1, p.1-46, 1977.

VIGNOLI, J.A. Efeito da osmolaridade do meio, permeabilização e imobilização de Zymomonas mobilis na produção de sorbitol. 2003, 52 f. Dissertação (Mestrado em Ciências e Tecnologia de Alimentos)-Universidade Estadual de Londrina, Londrina. 2003.

VIIKARI, L.; GISLER, R. By-products in the fermentation of sucrose by different Zymomonas strains. Applied Microbiology and Biotechnology, New York, v. 23, n. 3-4, p. 240-244, 1986.

VIGANTS, A.; HICKE, H.G.; MARX, S.P. A simple and efficient method for the purification of membrane-bound levansucrase from Zymomonas mobilis. Current Microbiology, New York, v. 42, p. 415-418, 2001.

YU, J.; YUE, G.; ZHONG, J.; ZHANG, X.; TAN, T. Imobilization of Saccharomyces cerevisiae to modified bagasse for etanol production. Renewable Energy, Oxford, v. 35, n. 6, p. 1130-1134, 2010. 